\title{
Combination of local Botulinum toxin A injections and standard oral drug treatment allows improvement of long- term pain management in severe post-herpetic neuralgia: $\mathrm{A}$ case report
}

\author{
Songjin Ri ${ }^{1}$, Max Nolte ${ }^{2}$ and Jörg Wissel ${ }^{1,3 *}$ \\ ${ }^{1}$ Neurology at Wittenbergplatz, Ansbacher Strasse 17-19, 10787 Berlin, Germany \\ ${ }^{2}$ Pain Clinic, Ansbacher Strasse 17-19, 10787 Berlin, Germany \\ ${ }^{3}$ Department of Neurorehabilitation, Vivantes Hospital Spandau, Neue Bergstrasse 6, 13585 Berlin, Germany
}

\begin{abstract}
Systematic reviews showed that Botulinum toxin A (BoTN A) may be helpful in controlling neuropathic pain like in Post-herpetic Neuralgia (PHN). We introduce a case report on the effects of a long-term management with intracutaneous BoTN A injections combined with classic drug treatment in a patient with severe PHN. The combination of regular BoTN A therapy every three month and oral drug treatment allows to reduce pain rating with VAS by $50 \%$ and suggested that this combination may be helpful for long term management of severe PHN.
\end{abstract}

\section{Introduction}

PHN is a very painful neuropathic status as the consequence of nerve injuries (e. g. demyelinisation, loss of axon, small-fiber-degeneration, reorganization in dorsal horn, neuroplastic central changes) due to herpes-zoster-infection. Definition includes duration of pain for more than 3 months $[1,2]$. First line treatment of PHN is anticonvulsant in combination with antidepressant, second or third line treatment today is using opioids, and local therapy with lidocaine or capsaicin. However, patients over 50 years of age often show severe side effects from first line oral treatments and opioids and are not satisfied by the duration of effects of current local treatment options. Usually aim of these chronic symptomatic therapies for $\mathrm{PHN}$ is to reduce about $30-50 \%$ of pain [3-5].

After the first report on the positive effect of BoTN A for pain in dystonia published by Brin et al. 1987, many studies on positive effects on chronic pain including modulation and management of spasticity associated pain and neurogenic pain, have been published [6-10]. The mechanism of pain reduction from BoTN A injections is still matter of discussion and included the effect on reducing release of various inflammation-mediated substances (substance P, glutamate, calcitonin gene - related peptide) by blocking exocytosis from BoNT A [6-10]. The recent meta-analysis of international association for the study of Pain (IASP) showed positive evidence of BoTN therapy for treatment of neuropathic pain and suggested intracutanous BoTN A injections as an effective therapy for focal neurogenic pain [11]. Some studies in PHN suggested positive short term effects of BoTN A therapy as alternative treatment in non-manageable PHN by classic medications [12-14]. In one double-blind, randomized controlled study, all 13 patients had reduction of pain with more than 50\% reduction in VAS under a single dose with Botox $100 \mathrm{IU} / 4 \mathrm{ml}$ and the effects were persisting for a median period of 16 weeks. As well short-term studies showed that BoNT A is a well-tolerated adjunctive therapy for severe PHN [12-
14]. Although the effects of multifocal intracutaneously injected BoTN A for the treatment of PHN have been known, long term efficacy and safety data of this local therapy approach in PHN is lacking and however this treatment in most countries still is used as "off-label" option yet and no reimbursement is established, i. g. in Germany and other European countries.

\section{Case}

The 56-years old male showed up first time in August 2013 and complained severe pain due to PHN in the area of left shoulder and ventral thorax. He stated that severe pain has begun following skin changes due to herpes zoster in June 2011. He experienced at that time pimples within several hours in the painful area between the spinal processes of Th3 - Th 11 and the medial line of left scapulae as well as on the body of sternum and some left skin areas of it (Figure 1). The constant severe pain niveau were juged by the patient with $7-8$ of 10 Visual Analog Scale (VAS), interrupted by severe shooting and electric-like pain episodes over seconds with levels up to 8 - 9 VAS even under regular oral drug treatments. Any accompanied diseases were unknown.

At the second day of symptoms with pimples herpes virus infection was diagnosed and only treated with $\mathrm{Zn}$ - ointment, no other treatment was introduced by the dermatologist. The scabbing and crusting of the skin injuries needed several weeks, but the severe pain, scares, pigments remained as post-herpetic neuralgia persisted. The severe

Correspondence to: Jörg W, MD, FRCP, Neurology at Wittenbergplatz, Ansbacher Strasse 17-19, 10787 Berlin, Germany. Tel: +49-30-21232828; E-mail: info@neuroreha-berlin.de

Key words: neuropathic pain, botulinum toxin, post-herpetic neuralgia

Received: May 10, 2018; Accepted: May 18, 2018; Published: March 21, 2018 
PHN was treated at first by dermatologist and later by a pain specialist, an anesthiologist. The patient had taken for PHN oral pregabalin up to $450 \mathrm{mg}$ per day, Morphine up to $80 \mathrm{mg}$ per day, additionally local treatment was introduced with capsaicin ointment and lidocaine plasters were applied by the therapist. He also took mirtazapin (NaSSA: Noradrenergic and Specific Serotonergic Antidepressant), and citalopram (SSRI), but all drugs applied had no positive effect for him. Serial lidocaine plaster also were applied locally on the affected skin, but had only a short time-relief of pain and therefore helped only a little. Additionally 6 acupuncture therapies for 3 weeks were introduced but had no reduction of pain intensity, but following acupuncture the very severe pain up to 8-9 VAS disappeared, but the constant pain level had been remained on levels of $7-8$ of 10 VAS even under constant drug treatment with morphine $80 \mathrm{mg}$ per day.

In August 2013 we introduced local intracutanous multi-point injections of BoNT A (Incobotulinum Toxin, product name:Xeomin $\odot$ ) with dosage per treatment session of 150 IU (IU=international units, dilution in normal saline to $100 \mathrm{IU} / 2 \mathrm{ml}$ ) to a total of up to 70-75 intra-/ subcutaneous injection points (one injection site within every $2 \mathrm{~cm}$ ) and a dosage per injection point of $2-2,5$ IU every 3 months (Figure 2). We used very small needles with 30 gauge and small tuberculin $(1 \mathrm{ml}$ volume) syringeous.

Following the first and the following 20 injection cycles usually three weeks following intracutanous BoTN A injections patient reported pain reduction from VAS 7 - 8 to pain levels VAS 4 - 5. Pain level reduction allows him to reduce Morphine to $40 \mathrm{mg}$ per day (half of the initial dose) for the following years. During the first and following injection cycles the patient reported pain reduction for up to 11 weeks and then increasing pain levels up to the pre-injection levels before follow-up injections.

Summing up the intracutanous injection of BoTN A were effective in reducing the intensities of PHN pains and enabled to reduce oral administrations of morphine, so that the patient asked for continuation of BoTN A injections. Up to now we have performed 20 injection
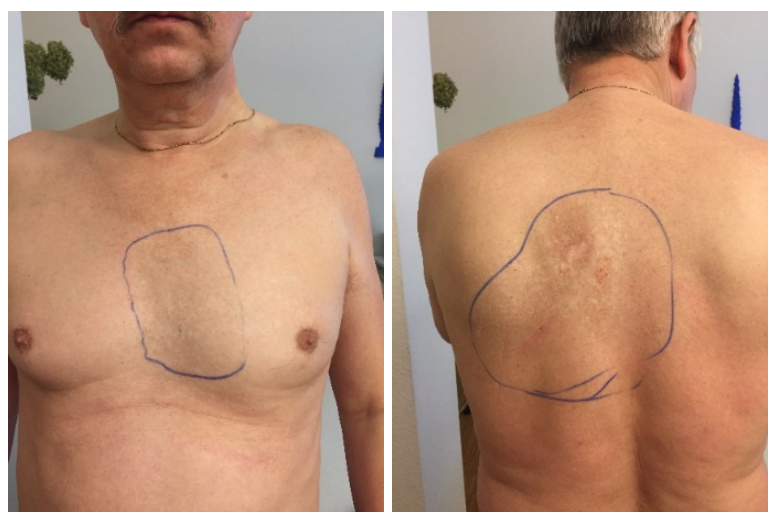

Figure 1: The borer of the painful areas were marked with blue lines

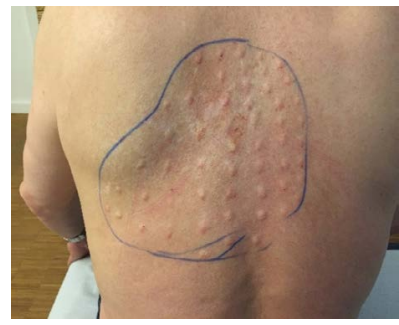

Figure 2: Intracutanous injections of Incobotulinum toxin (Xeomin). sessions. No side effects of BoTN injections were found over the reported treatment regime of 3 years. When compairing the costs of drug including BoTN A injections with the costs before this additional local therapy regime with BoNT A we found an slight elevation in costs of $30 \%$, which represents in Germany an elevation of 96 euros per month.

\section{Discussions}

To our opinion and in concordance with recent reports and systematic reviews, severe neuropathic pain like PHN often been found as one of the not completely resolved tasks in pain treatment for clinicians. In recent RCTs sub- and intracutaneous injections of BoNT A showed effectiveness in the treatment of neuropathic pain [11-14]. According to the German guideline for diagnosis and therapies in Neurology, the aim of therapies for PHN is to reduce $30-50 \%$ of pain and the effectiveness of therapies should be estimated after 2-4 weeks under sufficient dosage [3]. As in our patient, Apalla et al. observed effectiveness of BoTN A treatment for PHN 2-3 weeks after injection. All reported studies for PHN treatment estimated the effectiveness of BoTN A injections with effect size of greater than 50\% pain reduction [12-14].

We have performed now over 20 therapies with BoTN A focal injections in the patient reported as additional local therapy in the painful areas and found comparable neurogenic pain reduction of up to $50 \%$, from 7-8 / 10 VAS to 4 -5 / 10 VAS. Additionally, we were able to reduce dosage of morphine therapy to $50 \%$. We observed very good effectiveness starting mean 3 weeks after injections and last for up to 11 weeks, on average pain was reduced by $50 \%$. Although the positive effect of regular serial intracutanous BoTN A injections was observed in this patient with severe PHN for about 5 years, the pain never was completely eliminated by this treatment, but markedly reduced both subjectively and objectively and the patient never showed any side effect.

\section{Conclusion}

Our observations suggest that intracutaneous BoTN A injections could be used effectively as one important adjunctive local therapy for non treatable PHN. The costs for symptomatic management might be increase slightly by introducing BoNT A, but the additional effect results in major improvement and justify its use.

\section{References}

1. Wasner G (2012) Diagnostik neuropathischer Schmerzen, KAPITEL Kopfschmerzen und andere Schmerzen, Leitlinien für Diagnostik und Therapie in der Neurologie pp. 1-13.

2. Oxman MN, Levin MJ, Johnson GR, Schmader KE, Straus SE, et al. (2005) A vaccine to prevent herpes zoster and postherpetic neuralgia in older adults. N Engl J Med 352: 2271-84. [Crossref]

3. Baron R (2012) Pharmakologisch nicht interventionelle Therapie chronisch neuropathischer Schmerzen, Kapitel Kopfschmerzen und andere Schmerzen, Leitlinien für Diagnostik und Therapie in der Neurologie pp. 1-29.

4. Cohen JI (2013) Clinical practice: Herpes zoster. N Engl J Med 369: 255-263. [Crossref]

5. Sacks GM (2013) Unmet need in the treatment of postherpetic neuralgia. Am J Manag Care 19: S207-213. [Crossref]

6. Brin MF, Fahn S, Moskowitz C, Friedman A, Shale HM, et al. (1987) Localized injections of botulinum toxin for the treatment of focal dystonia and hemifacial spasm. Mov Disord 2: 237-254. [Crossref]

7. Durham PL, Cady R, Cady R (2004) Regulation of calcitonin gene-related peptide secretion from trigeminal nerve cells by botulinum toxin type A: implications for migraine therapy. Headache 44: 35-42. [Crossref]

8. Lucioni A, Bales GT, Lotan TL, McGehee DS, Cook SP, et al. (2008) Botulinum toxin type A inhibits sensory neuropeptide release in rat bladder models of acute injury and chronic inflammation. BJU Int 101: 366-370. [Crossref] 
Song JR (2018) Combination of local Botulinum toxin A injections and standard oral drug treatment allows improvement of long-term pain management in severe post-herpetic neuralgia: A case report

9. Mcmahon HT, Foran P, Dolly JO, Verhage M, Wiegant VM, et al. (1992) Tetanus toxin and botulinum toxins type $\mathrm{A}$ and $\mathrm{B}$ inhibit glutamate, gamma-aminobutyric acid, aspartate, and met-enkephalin release from synaptosomes. Clues to the locus of action. J Biol Chem 267: 21338-21343. [Crossref]

10. Wissel J, Ganapathy V, Ward AB, Borg J, Ertzgaard P, et al. (2016) OnabotulinumtoxinA Improves Pain in Patients with Post-Stroke Spasticity: Findings From a Randomized, Double-Blind, Placebo-Controlled Trial. J Pain Symptom Manage 52: 17-26. [Crossref]

11. Finnerup NB, Attal N, Haroutounian S, McNicol E, Baron R, et al. (2015) Pharmacotherapy for neuropathic pain in adults: a systematic review and meta-analysis. Lancet Neurol 14: 162-173. [Crossref]
12. Apalla Z, Sotiriou E, Lallas A, Lazaridou E, Ioannides D (2013) Botulinum Toxin A in Postherpetic Neuralgia, A Parallel, Randomized, Double-Blind, Single-Dose, Placebocontrolled Trial. Clin J Pain 29: 857-864. [Crossref]

13. Chen YW, Chuang SK (2017) Botulinum Toxin A Might Be an Alternative or Adjunct Therapy for the Treatment of Trigeminal and Postherpetic Neuralgia. J Evid Based Dent Pract 17: 259-261. [Crossref]

14. Shackleton T, Ram S, Black M, Ryder J, Clark GT, et al. (2016) The efficacy of botulinum toxin for the treatment of trigeminal and postherpetic neuralgia: a systematic review with meta-analyses. Oral Surg Oral Med Oral Pathol Oral Radiol 122: 61-71. [Crossref]

Copyright: (C2018 Song JR. This is an open-access article distributed under the terms of the Creative Commons Attribution License, which permits unrestricted use, distribution, and reproduction in any medium, provided the original author and source are credited. 